\title{
Software educacional: uma nova ferramenta de ensino de física para o nono ano do ensino fundamental
}

\author{
CORREA, G. A. ${ }^{*}$, GOMES, G. C. ${ }^{1}$, SOUSA, R. F. ${ }^{1}$, MERGULHÃO, C. J'.
}

1 Graduação em Física, Universidade Federal de Rondônia, Ji-Paraná, RO, Brasil.

2 Departamento de Física, Universidade Federal de Rondônia, Ji-Paraná, RO, Brasil.

*e-mail: gleiciac81@gmail.com

\section{Resumo}

A incorporação da tecnologia como aprendizagem pedagógica tem despertado discussões no meio educacional. Neste contexto, acredita-se na possibilidade do aprendizado de física com utilização de softwares. Assim, foi desenvolvido no nono ano do ensino fundamental este trabalho que utiliza um software interativo do tipo Applet como ferramenta pedagógica para ensinar conceitos de cinemática, com o objetivo de ensinar de forma prática e mais concreta conceitos sobre o MRU e MRUV através da simulação interativa. Para avaliar a abordagem utilizada, foram coletados dados dos alunos por meio de questionários antes, durante e depois da aplicação do software. Foi realizada uma análise percentual das respostas, buscando-se assim compreender a contribuição de softwares educativos na aprendizagem. Constatou-se que os softwares educativos aguçaram a curiosidade dos alunos e, que com a utilização deste recurso, o fato de errar não inibiu os alunos e até ajudou no processo de ensino-aprendizagem. Sendo assim cabe enfatizar a importância dos softwares educativos para o enriquecimento do processo de ensino-aprendizagem no Ensino Fundamental. A principal função dessa ferramenta não é substituir o professor, mas auxiliá-lo na mediação de processo de ensino-aprendizagem.

\begin{abstract}
The incorporation of technology as pedagogic learning has awakened discussions in the educational environment. In this context, we believe in the possibility of learning physics with the use of software. It was developed in the ninth year of elementary school this work that uses an interactive Applet-like software as a pedagogical tool to teach concepts of kinematics, with the objective of teaching in a practical and concrete concepts way about MRU and MRUV through interactive simulation. To evaluate the approach used, data were collected from the students through questionnaires before, during and after the application of the software. A percentage analysis of the answers was made, seeking to understand the contribution of educational software in learning. It was found that educational software sharpened the curiosity of the students and, with the use of this resource, the fact of error did not inhibit students and even helped in the teaching-learning process. There fore, it is important to emphasize the importance of educational software for the enrichment of teaching-learning process in Elementary School. The main function of this tool is not to replace the teachers, but to assist them in mediating the teaching-learning process.
\end{abstract}

Keyboards (Palavras chaves): Ensino Fundamental, Ensino-Aprendizagem com Software, Software interativo, Applets. 


\section{Introdução}

É possível superar antigos paradigmas e oportunizar um ensino de qualidade fazendo uso dos softwares? Como nós educadores podemos contribuir para 0 aproveitamento dessa ferramenta? A incorporação das tecnologias no ensino, embora já permanentes e irrevogáveis, constituem também assunto novo e de poucos esclarecimentos para a prática pedagógica. Atualmente, a informática está presente de maneira irreversível na nossa vida. É fundamental refletir sobre sua aplicação na educação. A educação tem que assumir um papel de adaptação às novas necessidades desta sociedade transformada. Hoje em dia, imaginar a tecnologia envolvida com o processo de aprendizagem não significa uma impossibilidade, mas sim uma possibilidade muito real e promissora. Segundo Pietrocola e Brockinton (2003) o uso do computador como ferramenta pedagógica pode ser bem eficiente no processo de ensino-aprendizagem de Física na escola [1].

Sendo um ramo da ciência, a Física já deve ser ensinada desde as series iniciais e portanto no Ensino Fundamental como defendem alguns pesquisadores (BARBOSA LIMA e CARVALHO, 2002) [2]. Rosa e Pecatti (2007, p.265) defende a importância de se ensinar Física desde as series iniciais devido ao seu caráter prático e útil para a vida. Assim, segundo estes e outros pesquisadores, o ensino de Física não pode ficar restrito apenas ao Ensino Médio. Assim, é necessário propor metodologias de ensino de Física específica para a realidade do Ensino Fundamental, e este trabalho visa contribuir para esta temática [3].

\subsection{Fundamentação teórica}

O uso da tecnologia trata-se de uma antecipação da abordagem científica que deveria ocorrer apenas em fases posteriores do ensino. Com dados levantados, propostas de ensino foram desenvolvidas com o propósito de contribuir para com a alfabetização Científica e Tecnológica (FOUREZ, 1997) dos estudantes do ensino fundamental [4]. Gamez (1998) afirma que o objetivo de um Software Educacional é o auxílio ao processo de ensino aprendizagem de uma determinada disciplina [5]. Segundo Valent (1993), o uso do computador no ensino de física através de softwares interativos pode facilitar a aprendizagem de física pois permite ações interativas que são bastante efetivas no ensino de física. E esta forma de aprendizagem que é designada por construcionista formará a base conceitual deste trabalho visto que a metodologia proposta neste trabalho se baseia no uso de um software interativo que simula eventos físicos [6] Neste trabalho, os applets obtidos do programa "PHET" foram usados como ferramenta pedagógica aplicada à disciplina de Física. Os applets são pequenos programas Java que podem ser inseridos dentro de páginas HTML e que constituem em simulações virtuais de eventos físicos, químicos, biológicos. O programa PhET (Physics Education Technology) é um site disponibilizado na Internet através do site http://phet.colorado.edu/index.php que pode ser utilizado gratuitamente e que disponibiliza vários applets de várias áreas do conhecimento, incluindo física [7].

À medida que o aluno manipula essas ferramentas interativas, as respostas são imediatamente animadas, assim ilustrando efetivamente as relações de causa e efeito, bem como várias representações relacionadas (movimento dos objetos, gráficos, leitura de números, etc.). O software possui uma série de características, como a facilidade quanto ao uso e entendimento, além de favorecer a assimilação dos conteúdos programáticos motivando e ganhando o interesse dos estudantes no tema em questão.

\subsection{Metodologia}

A metodologia empregada neste trabalho foi realizado na Escola Estadual de Ensino Fundamental e Médio Marcos Bispo da Silva como atividade do programa PIBID. Neste trabalho, além do software PHET, foram utilizados o laboratório de informática da escola e um data show. $O$ data show foi utilizado como ferramenta para facilitar a visualização do programa a todos os alunos ensinando-os executar os comandos do applets nos computadores da escola. Toda fundamentação teórica foi realizada antes da utilização do programa. Para a aplicação da pesquisa, foram selecionadas duas turmas do $9^{\circ}$ ano do ensino fundamental da referida 
escola, ambas com o mesmo professor regente na disciplina de física.

Inicialmente foi ministrada uma aula em ambas as turmas visando proporcionar uma fundamentação teórica sobre Movimento Retilíneo Uniforme (MRU) quando foi trabalhado os tópicos: ponto referencial, unidades de medida, os tipos de movimento, velocidade média, velocidade instantânea com o apoio do livro didático do nono ano. Posteriormente os alunos foram levados para o laboratório de informática onde foi feito o uso do applets propriamente dito. O applets utilizado neste trabalho é um que trata da simulação do Movimento Retilíneo Uniforme (MRU) e o Movimento Retilíneo Uniformemente Variado (MRUV) e é designado: "O Homem em movimento".

\subsubsection{Orientações gerais do programa}

Inicie 0 programa $P h E T$ simulations pelo site http://phet.colorado.edu/pt BR/. Neste simulador podemos representar os dois tipos do movimento: o Movimento Retilíneo Uniforme e o Movimento Retilíneo Uniformemente Variado onde os valores do espaço, da velocidade e da aceleração, podem ser alterados de modo que simulem o movimento. As figuras 1 e 2 mostram as imagens do software utilizado: O homem em movimento.

O homem em movimento.

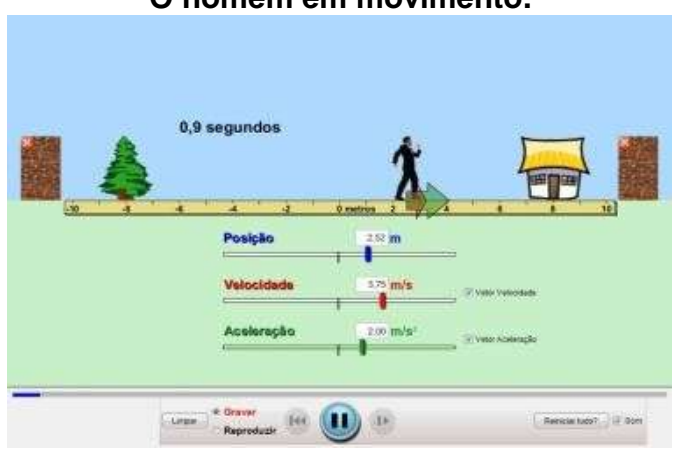

Figura 1: Fonte: https://phet.colorado.edu
O homem em movimento: Gráficos.

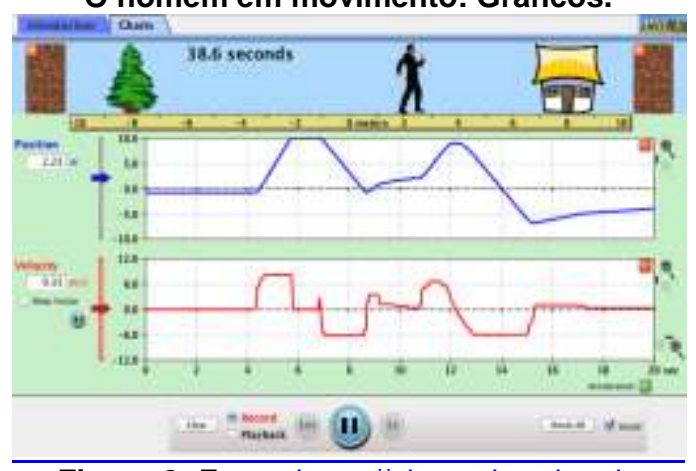

Figura 2: Fonte: https://phet.colorado.edu

A tabela 1 mostra alguns conceitos físicos trabalhados em sala de aula, no qual é possível visualizar e descrever através do software utilizado para o desenvolvimento da atividade aplicada em sala de aula anteriormente.

Tabela 1. Descrição do software simulador aplicado durante a pesquisa

\begin{tabular}{|c|c|c|}
\hline $\begin{array}{l}\text { Posição; } \\
\text { Velocidade; } \\
\text { Aceleração }\end{array}$ & $\begin{array}{l}\text { Interpretar, } \\
\text { prever e } \\
\text { desenhar } \\
\text { gráficos } \\
\text { (posição, } \\
\text { velocidade e } \\
\text { aceleração) } \\
\text { para situações } \\
\text { comuns. } \\
\text { Descrever seu } \\
\text { raciocínio para } \\
\text { entender os } \\
\text { gráficos. }\end{array}$ & $\begin{array}{l}\text { Para saber mais } \\
\text { sobre gráficos de } \\
\text { posição, } \\
\text { velocidade e } \\
\text { aceleração. Mova } \\
\text { o homenzinho } \\
\text { para lá e para cá } \\
\text { com o mouse e } \\
\text { trace o seu } \\
\text { movimento. Defina } \\
\text { a posição, } \\
\text { velocidade, ou } \\
\text { aceleração e deixe } \\
\text { a simulação mover } \\
\text { o homem para } \\
\text { você. }\end{array}$ \\
\hline
\end{tabular}

Antes, durante e após a aplicação do software no laboratório de informática, foi aplicado um questionário, com o intuito de extrair do aluno as principais dificuldades enfrentadas por ele no processo de ensino e aprendizagem sobre o tema em questão. No final, a verificação de aprendizagem obtida foi feita através da análise geral das respostas obtidas nos questionários propostos ao longo da aplicação do programa.

\section{Resultados e Discussão}


Com base nos questionários aplicados na atividade proposta e pela observação direta, pode-se afirmar que todos os que participaram da atividade apresentaram bom rendimento de modo geral. Os participantes eram 46, duas turmas do 9ano, sendo elas o 9ano B e 9oano D. Destes, destacamos que todos alunos participaram da aula interativa com a utilização do Phet. Na avaliação dos resultados foram elaborados e aplicados 3 questionários, sendo o primeiro deles contendo 6 questões que tinham como objetivo quantificar a atitude dos alunos em relação aos objetos de aprendizagem.

O primeiro questionário utilizado foi aplicado após a aula expositiva do conteúdo e antes da aplicação software e, investigou os seguintes pontos:

Você já usou algum computador em casa ou na escola para simular um experimento físico?

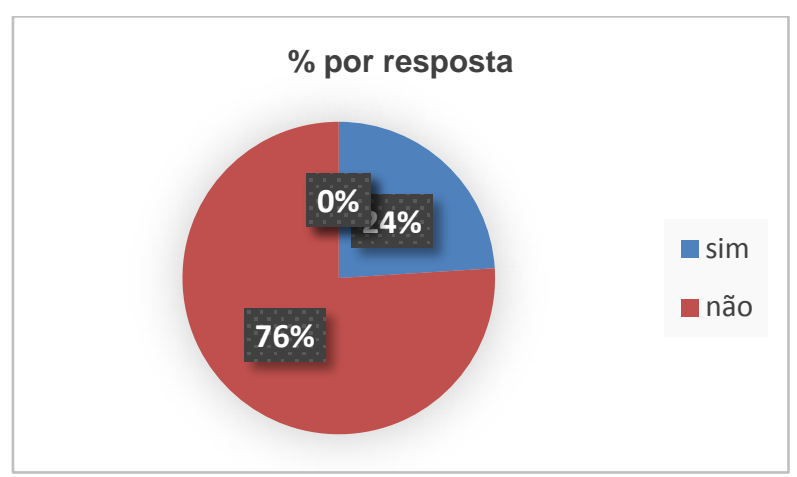

\section{Gráfico 1: Percentual por resposta ao uso do}

computador (antes da aplicação do Software).

Verifica-se que através de um questionário simples aplicado em ambas as turmas a quantidade de alunos que fazem ou já fizeram o uso de um computador em casa para simular um experimento físico é baixo, apesar da maioria dos alunos ter acesso a internet nos dias atuais.

Já as perguntas seguintes, foram relacionadas ao movimento, os alunos foram bem inconsistentes nas respostas e, na maioria dos casos não sabiam responder ou, por não saberem as respostas optaram por não responder às perguntas.

Ainda assim dentro dos $40 \%$ dos alunos que se arriscaram em responder $50 \%$ de um total de 13 alunos acertaram as questões que se referiam ao movimento, os que erraram, foi por falta de informação a respeito do conteúdo, já que os alunos do nono ano ainda não são familiarizados com a matéria de física.

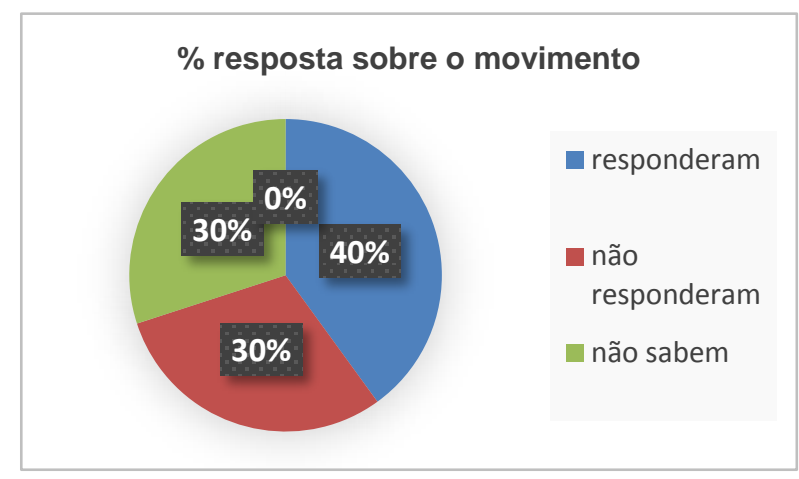

Gráfico 2: Percentual por resposta sobre o MRU (antes da aplicação do Software).

Os gráficos 1 e 2 apresentados aqui, nos mostra que o conhecimento em física em particular para alunos que cursam o nono ano em redes públicas de ensino ainda são muito abstratos, pois apesar da maioria ter acesso ao computador nos dias de hoje, o interesse em buscar conhecimento através de um simulador é bem pequena e, também os conhecimentos prévios quando se fala de física são mínimos.

O segundo questionário utilizado foi aplicado após a aula expositiva, durante a aplicação do software e investigou os seguintes pontos, contendo 4 questões:

\section{Referentes ao experimento interativo}

1. O que aconteceu com o homem quando a velocidade era igual a zero(0)?

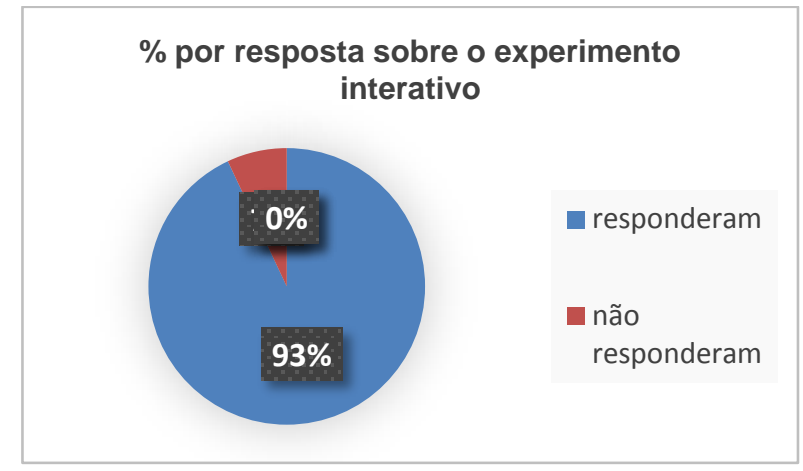

Gráfico 3: Percentual por resposta sobre o MRU (durante a aplicação do Software).

Podemos verificar na questão 01 do segundo questionário, que os alunos entenderam o tema, após a exposição de conceitos iniciais a respeito de física, por ser um tema inicial relativo a velocidade e que foi facilmente analisado no software, os $93 \%$ responderam 
corretamente, mesmo sem saber se iriam acertar ou não.

2. O que acontece quando não existe aceleração no movimento? Explique.

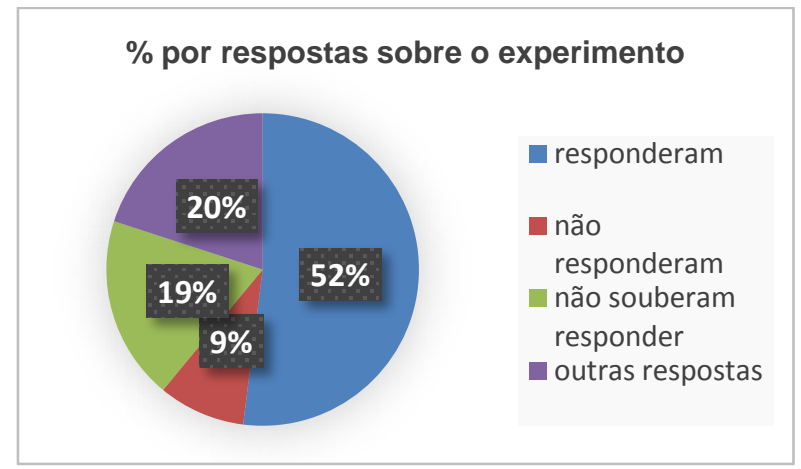

Gráfico 4: Percentual por resposta sobre o MRU

(durante a aplicação do Software).

Na questão 02 podemos notar claramente que ainda há um interesse no assunto porém alguns alunos não responderam, cerca de $9 \%$, e 19\% não sabiam sobre o conteúdo relativo ao movimento acelerado, 24 alunos responderam a questão corretamente sendo respectivamente os $52 \%$ mostrados no gráfico acima e, mesmo os que erraram interagiram com a aplicação do applet.

3. O que acontece quando aumentamos a velocidade?

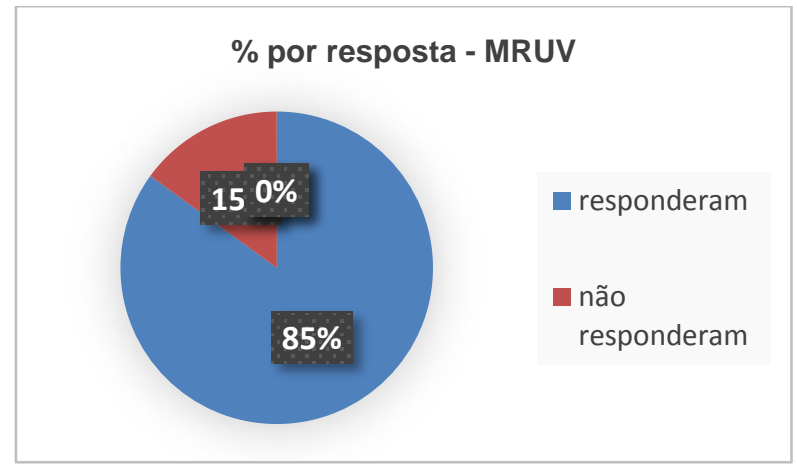

Gráfico 5: Percentual por resposta sobre o MRUV (durante a aplicação do Software).

Nota-se que, os alunos mesmo não sabendo a resposta ou errando contribuíram para que a aula interativa fosse possível, de $85 \%$ dos alunos que responderam ao questionário respectivamente $32 \%$ dos mesmos acertaram as respostas, mostrando resultados satisfatório dentro do que se era esperado no uso do aplicativo.

4. Explique porque o tempo de chegada diminui quando aumentamos a aceleração.

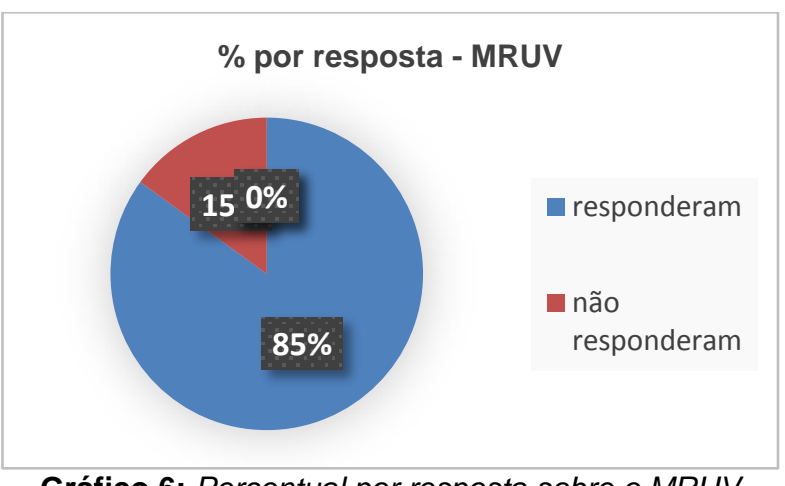

Gráfico 6: Percentual por resposta sobre o MRUV (durante a aplicação do Software).

Apenas 15\% dos alunos não responderam esta questão, ou por não saber sobre o conteúdo ou por desinteresse. Sendo na sua maioria $85 \%$ mostraram total interesse pela atividade desenvolvida, sendo que houve um aumento significativo de acertos em relação a questão anterior, pois $41 \%$ dos alunos que responderam a esta questão acertaram.

O terceiro questionário foi aplicado após a realização da atividade com o uso do software buscando entender alguns pontos a respeito do movimento e, do interesse dos alunos sobre o assunto antes da abordagem sobre o tema e a aplicação.

Este questionário investigou os seguintes pontos, contendo 3 questões:

1. Qual a importância do Movimento uniforme no seu Dia-Dia?

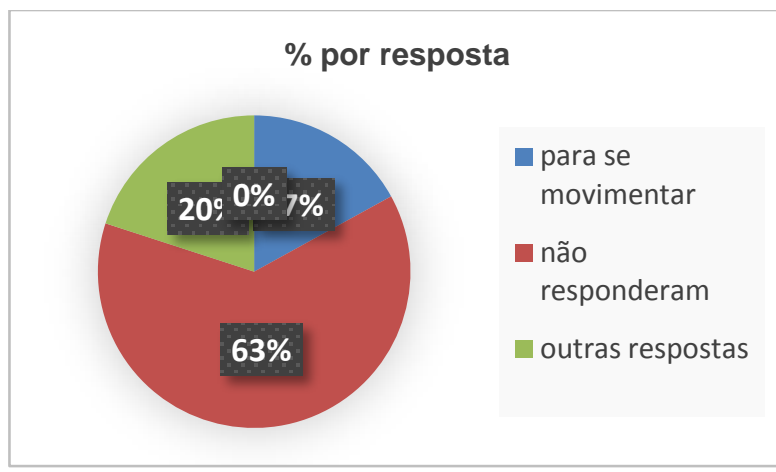

Gráfico 7: Percentual por resposta (após a aplicação do Software).

Tratando-se de uma questão do dia-dia apenas 17\% dos alunos demostraram interesse a respeito do movimento, ainda assim um porcentagem satisfatória, já que os mesmos ainda não tiveram um contato mais profundo de física e, possivelmente por ser um tempo totalmente reduzido neste questionário, nota-se que $63 \%$ optaram por não responder a esta questão. 
2. Você já havia parado pra pensar sobre o Movimento realizado por uma pessoa andando em uma rua?

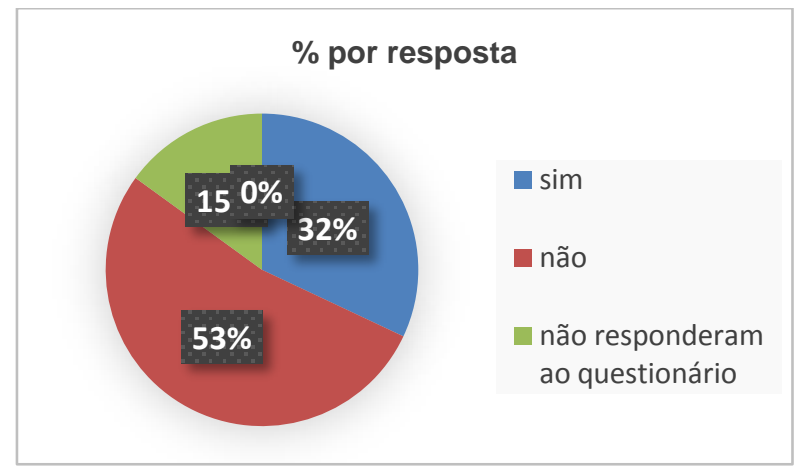

Gráfico 8: Percentual por resposta sobre o movimento (após a aplicação do Software).

Como a física é apenas introdutória no nono ano do ensino fundamental, é visível no gráfico acima que os alunos ainda não fazem observações físicas a respeito do movimento, como esperado apenas $32 \%$ responderam que já haviam pensado sobre o movimento realizado em uma rua. Sendo que na sua maioria $53 \%$ nunca haviam pensado nisto como um fato físico.

3. O estudo com o simulador fez com que você pensasse mais nos acontecimentos na natureza em seu dia-dia?

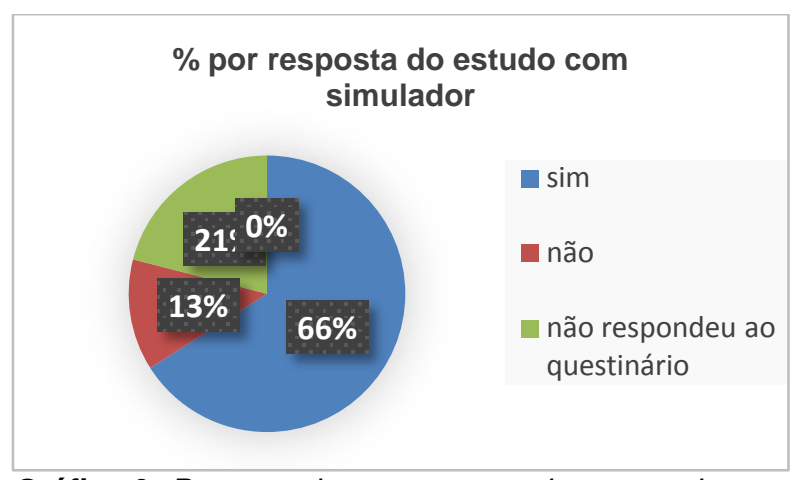

Gráfico 9: Percentual por resposta sobre o estudo com o simulador (após a aplicação do Software).

O uso do simulador se torna uma ferramenta útil para o ensino e demonstração física no ensino fundamental, observa-se no gráfico acima que, quando é perguntado ao aluno se o uso do simulador fez com que pensassem mais nos acontecimentos na natureza em seu dia-dia $66 \%$ responderam que sim, demonstrando que o resultado de aplicações de simuladores durante a aula de física para o ensino fundamental seja compreendida de uma maneira mais simplificada e tornando o aprendizado de física mais satisfatório para os mesmos.

\section{Conclusão}

Diante da análise dos questionários aplicados em sala de aula com alunos do nono ano do ensino fundamental, pôde-se compreender que o significado da utilização do software educativo só é possível considerando-se o dinamismo da interação que esse tipo de recurso proporciona em situação de aprendizagem. Nesse caso em particular o tema abordado foram temas introdutórios a disciplina de física. Os gráficos demonstram claramente a interação dos alunos e a curiosidade de alguns, visto que, a maioria não tem acesso ou não tem interesse por simuladores ou similares dentro ou fora do ambiente escolar utilizando esse tipo de ferramenta. Esse envolvimento talvez seja devido a primeira experiência com esse tipo de atividade. Sendo assim significativo o interesse pelo software, com a participação de todos os alunos presentes. O conhecimento do tema era razoável, haja vista que o nono ano é uma turma em transição para o ensino médio, no qual é aplicada introdução de física para o ensino médio.

\section{Referências}

[1] PIETROCOLA, M.; BROCKINTON, G. Recursos Computacionais Disponíveis na Internet para o Ensino de Física moderna e Contemporânea. In: ENCONTRO DE PESQUISA EM ENSINO DE CIÊNCIAS, 3, 2003, Bauru. Atas... Bauru: ABRAPEC, 2003.

[2] BARBOSA Lima, M. C.; Carvalho, A. M. P. Exercícios de raciocínio em três linguagens: ensino de Física nas séries iniciais. Ensaio - Pesquisa em Educação em Ciências, v. 4, n.1, 2002.

[3] ROSA, C. W.; ROSA, A. B.; PECATTI, C. Atividades experimentais nas séries iniciais: relato de uma investigação. Revista Electrónica de Enseñanza de lãs Ciências, v. 6, n. 2, p. 265. 2007.

[4] FOUREZ, G. Alfabetização Científica y Tecnológica. Argentina: Adiciones Coligue, 1997. 
[5] GAMEZ, Luciano. TICESE-Técnica de inspeção de conformidade ergonômica de Software educacional. Dissertação de Mestrado submetida à UnB, 1998.

[6] VALENTE, JA (1993). Computadores e conhecimento: repensando a educação. Campinas: Gráfica da UNICAMP.
[7] PhET Interactive Simulations. Disponível em: http://phet.colorado.edu/index.php, acesso em: $21 \mathrm{de}$ setembro de 2016. 